\title{
Impact of mild therapeutic hypothermia on bioavailability of ticagrelor in patients with acute myocardial infarction after out-of-hospital cardiac arrest
}

\author{
Julia M. Umińska ${ }^{1}$, Jakub Ratajczak², Katarzyna Buszko', \\ Przemysław Sobczak ${ }^{2}$, Wiktor Sroka ${ }^{4}$, Michał P. Marszałł \\ Piotr Adamski ${ }^{2}$, Klemen Steblovnik ${ }^{5}$, Marko Noč ${ }^{5}$, Jacek Kubica ${ }^{2}$ \\ ${ }^{1}$ Department of Geriatrics, Collegium Medicum, Nicolaus Copernicus University, Bydgoszcz, Poland \\ ${ }^{2}$ Department of Cardiology and Internal Medicine, Collegium Medicum, \\ Nicolaus Copernicus University, Bydgoszcz, Poland \\ ${ }^{3}$ Department of Theoretical Foundations of Biomedical Science and Medical Informatics, \\ Collegium Medicum, Nicolaus Copernicus University, Bydgoszcz, Poland \\ ${ }^{4}$ Department of Medicinal Chemistry, Collegium Medicum, \\ Nicolaus Copernicus University, Bydgoszcz, Poland \\ ${ }^{5}$ Center for Intensive Internal Medicine, University Medical Center Ljubljana, Slovenia
}

\begin{abstract}
Background: Out-of-hospital cardiac arrest (OHCA) frequently occurs in the early phase of acute myocardial infarction (MI). Survivors require percutaneous coronary intervention (PCI) with concomitant dual antiplatelet therapy. Target temperature management, including mild therapeutic hypothermia (MTH), should be applied in comatose patients after resuscitation. However, an increased risk of stent thrombosis in patients undergoing hypothermia is observed. The aim of this study was to assess the impact of MTH on pharmacokinetics of ticagrelor in cardiac arrest survivors with MI treated with MTH and PCI.
\end{abstract}

Methods: In a prospective, observational, single-center study pharmacokinetics of ticagrelor were evaluated in $41 \mathrm{MI}$ patients, including 11 patients after OHCA undergoing MTH (MTH group) and 30 MI patients without OHCA and MTH (no-MTH group). Blood samples were drawn before administration of a $180 \mathrm{mg}$ ticagrelor loading dose, and $30 \mathrm{~min}, 1,2,4,6,12$, and $24 \mathrm{~h}$ after the loading dose. Results: In patients treated with MTH total exposure to ticagrelor during the first $12 \mathrm{~h}$ after the loading dose and maximal plasma concentration of ticagrelor were significantly lower than in the no-MTH group $\left(A U C_{(0-12)}: 3403 \pm 2879\right.$ vs. $8746 \pm 5596 \mathrm{ng} \cdot \mathrm{h} / \mathrm{mL}$, difference: $61 \%, p=0.01 ; C_{\max } \cdot 475 \pm 353$ vs. $1568 \pm 784 \mathrm{ng} / \mathrm{mL}, p=0.0002)$. Time to achieve maximal ticagrelor plasma concentration was also delayed in the MTH group ( $t_{\max }$ for ticagrelor: 12 [6-24] vs. 4 [2-12] $h, p=0.01$ ).

Conclusions: Bioavailability of ticagrelor was substantially decreased and delayed in MI patients treated with MTH after OHCA.

Trial registration: ClinicalTrials.gov Identifier: NCT02611934 (Cardiol J 2020; 27, 6: 780-788)

Key words: cardiac arrest, myocardial infarction, hypothermia, ticagrelor, platelets, pharmacokinetics

Address for correspondence: Julia M. Umińska, MD, Department of Geriatrics, Collegium Medicum, Nicolaus Copernicus University, ul. M. Skłodowskiej-Curie 9, 85-094 Bydgoszcz, Poland, tel: +48 5258549 00, fax: +48 525854921 , e-mail: julia.m.kubica@gmail.com

Received: 18.02.2019 Accepted: 20.02.2019 


\section{Introduction}

Out-of-hospital cardiac arrest (OHCA) frequently occurs in the early phase of acute myocardial infarction (MI). OHCA survivors presenting symptoms of acute MI require primary percutaneous coronary intervention (PCI) with concomitant dual antiplatelet therapy (DAPT), including acetylsalicylic acid (ASA) and a $\mathrm{P}_{2} \mathrm{Y}_{12}$ receptor inhibitor [1-4]. Early administration of antiplatelet agents is necessary as the highest risk of stent thrombosis was reported within the early phase after stent implantation [5]. Ticagrelor and prasugrel are the preferred $\mathrm{P} 2 \mathrm{Y}_{12}$ inhibitors in this clinical setting [6-11]. In patients remaining in a coma after resuscitation targeted temperature management should be applied with a constant core temperature between $32^{\circ} \mathrm{C}$ and $36^{\circ} \mathrm{C}$ [12].

It has been shown that plasma concentrations of ticagrelor and its active metabolite (AR-C124910XX) are diminished in patients with ST-segment elevation MI. This effect is even more pronounced with concomitant morphine administration [13-19]. In survivors of OHCA due to MI additional factors including mild therapeutic hypothermia (MTH) may further impede ticagrelor's bioavailability [20-22]. The decreased antiplatelet effect of ticagrelor caused by hindered pharmacokinetics might be responsible for an increased risk of stent thrombosis in resuscitated patients undergoing MTH despite DAPT [23, 24].

Thus, the present study was designed [21] and performed using a prospective observational approach to assess pharmacokinetics of ticagrelor in MI patients after OHCA treated with primary PCI and MTH.

\section{Methods}

The study was designed and performed as a phase IV, single-center, investigator-initiated, prospective, observational trial aimed to compare pharmacokinetics of ticagrelor between MI patients after OHCA treated with primary PCI and MTH (MTH group) and MI patients without OHCA treated with primary PCI (no-MTH group). The inclusion as well as exclusion criteria for both groups have been previously published [21].

Mild therapeutic hypothermia was defined as a body core temperature below $34^{\circ} \mathrm{C}$, with a target temperature of $33^{\circ} \mathrm{C}$. In order to reach the target temperature and maintain it over subsequent $24 \mathrm{~h}$, intravascular cooling supported by cold saline $\left(4^{\circ} \mathrm{C}\right)$ infusion and external cooling at the induction phase of MTH were used. The MTH procedure applied in this study has also been previously described [21].

All study participants received treatment according to the European Society of Cardiology guidelines. All patients included in the trial received a $300 \mathrm{mg}$ loading dose (LD) of plain ASA and a $180 \mathrm{mg} \mathrm{LD}$ of ticagrelor in integral tablets administered through a nasogastric tube in the MTH group, and orally in the no-MTH group.

The study was conducted in accordance with the Declaration of Helsinki and Good Clinical Practice guidelines and was approved by the Ethics Committee of The Nicolaus Copernicus University in Torun, Collegium Medicum in Bydgoszcz (approval number KB 339/2015). All MI patients without MTH provided written, informed consent to participate in the study before enrollment, as additional blood sampling was required. In patients treated with MTH due to OHCA it was not possible to obtain informed consent, however these patients did not require additional sampling outside the standard protocol of MTH monitoring. This is a sub-study of the Mild Therapeutic Hypothermia for Patients with Acute Coronary Syndrome and Cardiac Arrest Treated with Percutaneous Coronary Intervention (UNICORN) study (ClinicalTrials.gov Identifier: NCT02611934).

\section{Endpoints}

The primary endpoint of this study was the area under the plasma concentration-time curve $\left(\mathrm{AUC}_{(0-12)}\right)$ for ticagrelor during the first $12 \mathrm{~h}$ after administration of LD. Secondary endpoints included $\mathrm{AUC}_{(0-12)}$ for AR-C124910XX, $\mathrm{AUC}_{(0-6)}$ for ticagrelor and AR-C124910XX, maximum concentration of ticagrelor and AR-C124910XX for $12 \mathrm{~h}$ $\left(\mathrm{C}_{\max 12}\right)$, and time to $\mathrm{C}_{\max }\left(\mathrm{t}_{\max }\right)$ for ticagrelor and AR-C124910XX, plasma concentrations of ticagrelor and AR-C124910XX at baseline, and $30 \mathrm{~min}$, $1,2,4,6,12$, and $24 \mathrm{~h}$ after ticagrelor $\mathrm{LD}$.

\section{Evaluation of pharmacokinetics}

Blood samples for pharmacokinetic evaluation were drawn before administration of a $180 \mathrm{mg}$ ticagrelor $\mathrm{LD}$, and $30 \mathrm{~min}, 1,2,4,6,12$, and $24 \mathrm{~h}$ after LD. Ticagrelor and AR-C124910XX plasma concentrations were analyzed using liquid chromatography coupled with tandem mass spectrometry. Analysis was performed using Shimadzu UPLC Nexera X2 system consisting of LC-30AD pumps, SIL-30AC Autosampler, CTO-20AC column oven, FCV-20-AH2 valve unit, and DGU-20A5R degasser coupled with Shimadzu 8030 ESI-QqQ mass spec- 
Table 1. Characteristics of patients enrolled in the study group - mild therapeutic hypothermia (MTH) and control group (no-MTH).

\begin{tabular}{|c|c|c|c|}
\hline & MTH group $(n=11)$ & No-MTH group $(n=30)$ & $\mathbf{P}$ \\
\hline Gender, male & $73 \%(8)$ & $80 \%(24)$ & NS \\
\hline Age [years] & $62.0 \pm 11.9$ & $64.4 \pm 10.3$ & NS \\
\hline \multicolumn{4}{|l|}{ History of: } \\
\hline Coronary artery disease & $27 \%(3)$ & $20 \%(6)$ & NS \\
\hline Acute myocardial infarction & $27 \%(3)$ & $13 \%(4)$ & NS \\
\hline $\mathrm{PCl}$ & $27 \%(3)$ & $20 \%(6)$ & NS \\
\hline CABG & $0 \%(0)$ & $0 \%(0)$ & NS \\
\hline Heart failure & $9 \%(1)$ & $0 \%(0)$ & NS \\
\hline Arterial hypertension & $54.5 \%(6)$ & $47 \%(14)$ & NS \\
\hline Stroke & $9 \%(1)$ & $0 \%(0)$ & NS \\
\hline Smoking & $45.5 \%(5)$ & $60 \%(18)$ & NS \\
\hline \multicolumn{4}{|l|}{ Acute myocardial infarction: } \\
\hline STEMI & $54.5 \%(6)$ & $60 \%(18)$ & NS \\
\hline NSTEMI & $45.5 \%(5)$ & $40 \%(12)$ & \\
\hline \multicolumn{4}{|l|}{ Number of vessels diseased: } \\
\hline 1 & $36.4 \%(4)$ & $27 \%(8)$ & NS \\
\hline 2 & $18.2 \%(2)$ & $43 \%(13)$ & \\
\hline 3 & $45.5 \%(5)$ & $30 \%(9)$ & \\
\hline \multicolumn{4}{|l|}{ TIMI before $\mathrm{PCl}$ : } \\
\hline 0 & $45.5 \%(5)$ & $40 \%(12)$ & NS \\
\hline 1 & $27 \%(3)$ & $6.6 \%(2)$ & \\
\hline 2 & $9 \%(1)$ & $6.6 \%(2)$ & \\
\hline 3 & $18.2 \%(2)$ & $47 \%(14)$ & \\
\hline \multicolumn{4}{|l|}{ TIMI after PCI: } \\
\hline 0 & $0 \%(0)$ & $0 \%(0)$ & NS \\
\hline 1 & $0 \%(0)$ & $3.3 \%(1)$ & \\
\hline 2 & $0 \%(0)$ & $0 \%(0)$ & \\
\hline 3 & $100 \%(11)$ & $96.7 \%(29)$ & \\
\hline \multicolumn{4}{|l|}{ Number of used stents: } \\
\hline 0 & $0 \%(0)$ & $3.3 \%(1)$ & NS \\
\hline 1 & $54.5 \%(6)$ & $70 \%(21)$ & \\
\hline 2 & $36.4 \%(4)$ & $20 \%(6)$ & \\
\hline 3 or more & $9 \%(1)$ & $6.6 \%(2)$ & \\
\hline \multicolumn{4}{|l|}{ Echocardiography: } \\
\hline LVEF [\%] & $34.0 \pm 11.6$ & $45.5 \pm 7.9$ & 0.003 \\
\hline
\end{tabular}

CABG - coronary artery bypass grafting; LVEF — left ventricular ejection fraction; NS — non significant; NSTEMI - non-ST-segment elevation myocardial infarction; PCI — percutaneous coronary intervention; STEMI — ST-segment elevation myocardial infarction; TIMI — Thrombolysis in Myocardial Infarction

trometer. Lower limits of quantification were 4.69 $\mathrm{ng} / \mathrm{mL}$ for both ticagrelor and AR-C124910XX [25].

\section{Statistical analysis}

All calculations were performed using Statistica 13.0 package (StatSoft, Tulsa, OK, USA). Continuous variables are presented as means \pm standard deviation and median with quartiles.
For categorical variables, counts with percentages have been used. Due to non-normal data distribution (as verified with the Shapiro-Wilk test), comparisons between both groups at each measurement point were performed with the Mann-Whitney test. For comparison of categorical variables, the $\chi^{2}$ test or the Fisher exact test was applied as appropriate. In all cases $p$ values $\leq 0.05$ were considered significant. 


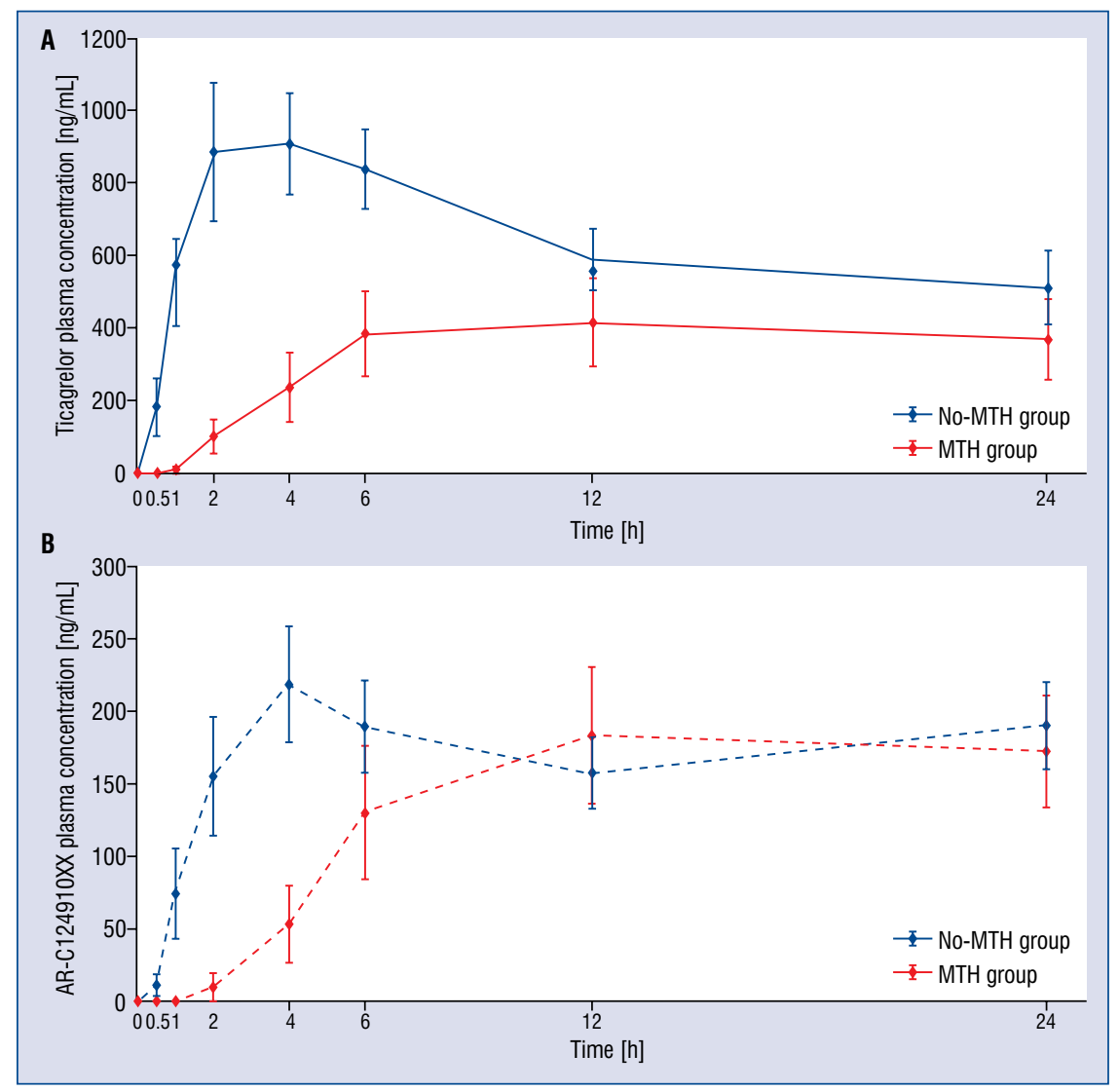

Figure 1. The exposures to ticagrelor (A) and AR-C124910XX (B) within $24 \mathrm{~h}$ after the administration of ticagrelor loading dose $(180 \mathrm{mg})$. Only patients with complete data were included; MTH - mild therapeutic hypothermia.

\section{Results}

Overall $43 \mathrm{MI}$ patients were included in the study. There were no significant differences in baseline characteristics between both groups, except higher left ventricular ejection fraction in the no-MTH group (Table 1). Initially, 13 patients were enrolled into the MTH group, however complete data (results from all study time-points) were available for only 7 patients, as 4 of them had died before $24 \mathrm{~h}$ from the beginning of the MTH procedure. Additionally, 2 patients from MTH group were excluded from the analysis of the primary end point due to hemolysis in blood samples that precluded complete pharmacokinetic evaluation. Ventricular fibrillation was the first recorded rhythm during cardiac arrest in all 13 patients. The no-MTH group consisted of $30 \mathrm{MI}$ patients without OHCA treated with primary PCI.

Analysis of bioavailability of ticagrelor and AR-C124910XX revealed pronounced differences between compared groups (Fig. 1). Total exposures to both ticagrelor and AR-C124910XX within the first $12 \mathrm{~h}$ after LD administration, as measured by the $\mathrm{AUC}_{(0-12)}$ was significantly lower in MTH group vs. no-MTH group for ticagrelor $\left(\mathrm{AUC}_{(0-12)}\right.$ : $3403 \pm 2879$ vs. $8746 \pm 5596 \mathrm{ng} \cdot \mathrm{h} / \mathrm{mL}$, corresponding to a difference of $61 \%, \mathrm{p}=0.01$ ), while no difference for AR-C124910XX was present $\left(\mathrm{AUC}_{(0-12)}: 1195 \pm 1022\right.$ vs. $1963 \pm 1726 \mathrm{ng} \cdot \mathrm{h} / \mathrm{mL}$, difference: $40 \%, \mathrm{p}=0.3$ ). The observed differences were more pronounced during the first $6 \mathrm{~h}$ after ticagrelor $\mathrm{LD}\left(\mathrm{AUC}_{(0-6)}\right.$ for ticagrelor: $1012 \pm$ \pm 981 vs. $4487 \pm 3608 \mathrm{ng} \cdot \mathrm{h} / \mathrm{mL}$, difference: $77 \%$, $\mathrm{p}=0.01 ; \mathrm{AUC}_{(0-6)}$ for AR-C124910XX: $253 \pm 281$ vs. $922 \pm 980 \mathrm{ng} \cdot \mathrm{h} / \mathrm{mL}$, difference: $73 \%, \mathrm{p}=0.06$ ). The maximal plasma concentration of ticagrelor was lower in MTH group vs. no-MTH group $\left(\mathrm{C}_{\max }\right.$ for ticagrelor: $475 \pm 353 \mathrm{vs} .1568 \pm 784 \mathrm{ng} / \mathrm{mL}$, $\mathrm{p}=0.0002$ ), whereas there were no differences in maximal concentration of the metabolite between the groups $\left(\mathrm{C}_{\max }\right.$ for AR-C124910XX: $203 \pm 121$ vs. $337 \pm 186 \mathrm{ng} / \mathrm{mL} ; \mathrm{p}=0.1$ ). Time to achieve maximal plasma concentrations was delayed for both ticagrelor and AR-C124910XX in MTH group vs. no-MTH group ( $\mathrm{t}_{\max }$ for ticagrelor: 12 [6-24] vs. 4 [2-12] h, $\mathrm{p}=0.01 ; \mathrm{t}_{\max }$ for AR-C124910XX: 18 [12-24] vs. 4 [4-12] h, $\mathrm{p}=0.01$ ) (Fig. 1). 


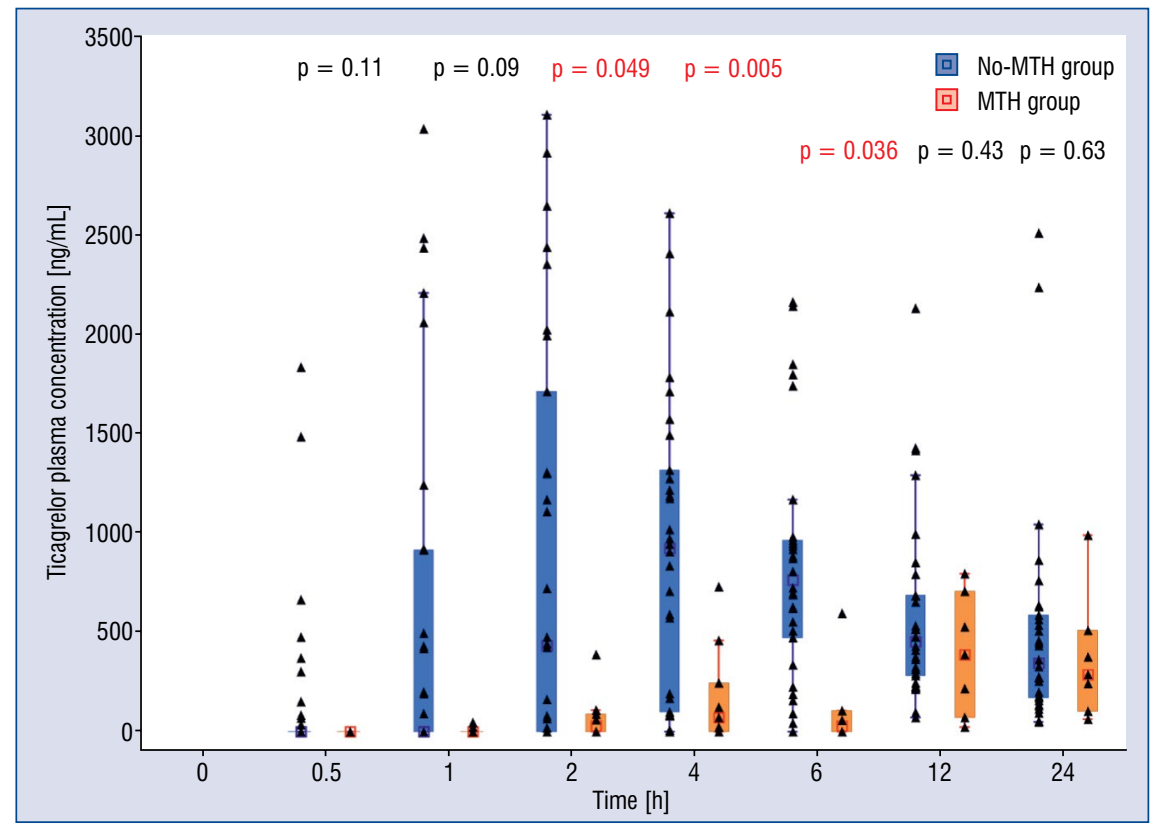

Figure 2. Plasma concentrations of ticagrelor over in mild therapeutic hypothermia (MTH) group $(n=11)$ vs. no-MTH group $(\mathrm{n}=30)$. All available data presented.

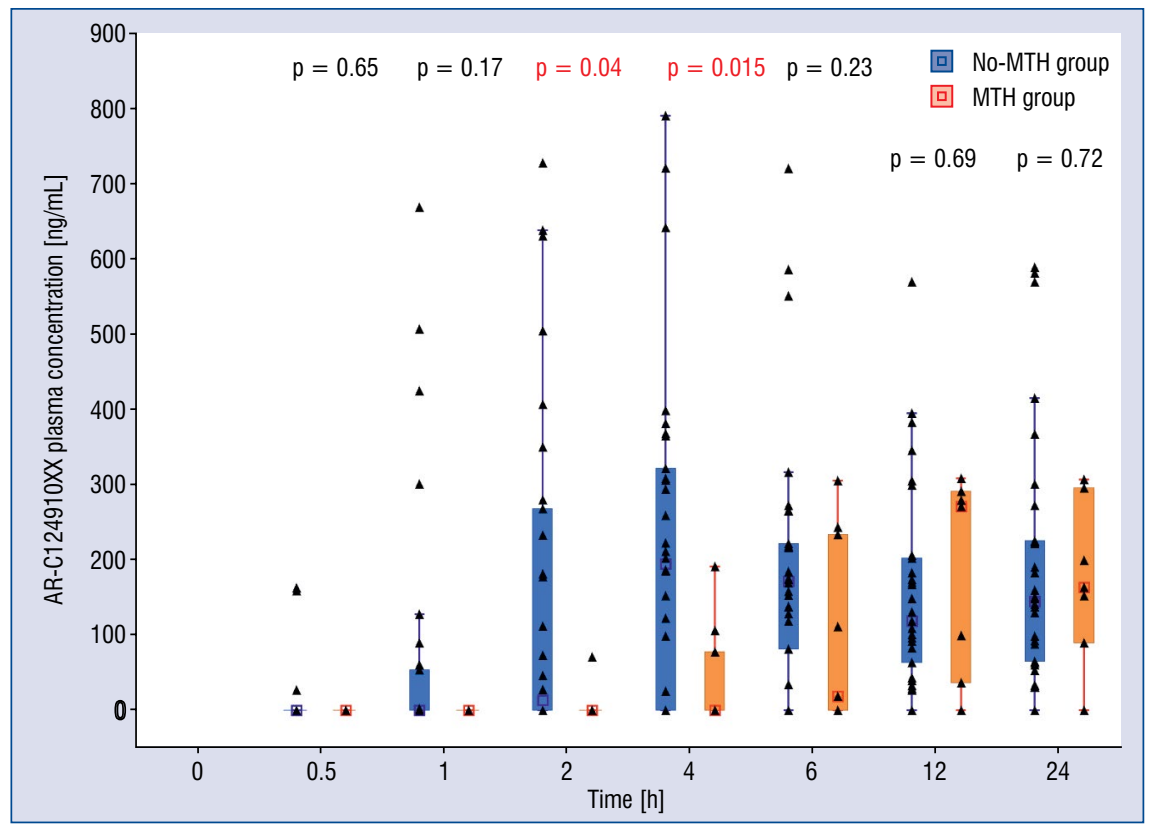

Figure 3. Plasma concentrations of AR-C124910XX over in mild therapeutic hypothermia (MTH) group ( $\mathrm{n}=11)$ vs. no-MTH group $(\mathrm{n}=30$ ). All available data presented.

Comparison of plasma concentrations of ticagrelor in consecutive time-points showed significant discrepancy between the groups with higher drug concentrations seen in no-MTH group, starting from the first hour after administration of ticagrelor LD (Fig. 2). The difference reached level of statistical significance at 2,4 and $6 \mathrm{~h}$ post-LD
(no-MTH group vs. MTH group, respectively: $882.45 \pm 1041.77$ vs. $70.36 \pm 118.70 \mathrm{ng} / \mathrm{mL}$, $\mathrm{p}=0.049 ; 904.43 \pm 758.31$ vs. $183.41 \pm 255.35$ $\mathrm{ng} / \mathrm{mL}, \mathrm{p}=0.005 ; 834.58 \pm 595.51$ vs. $382.09 \pm$ $\pm 329.72 \mathrm{ng} / \mathrm{mL}, \mathrm{p}=0.036)$. Higher concentrations of AR-C124910XX in no-MTH group were present up to $6 \mathrm{~h}$ (Fig. 3), and this difference was significant 
at 2 and $4 \mathrm{~h}$ (no-MTH group vs. MTH group, respectively: $155.25 \pm 223.16$ vs. $7.10 \pm 22.46 \mathrm{ng} / \mathrm{mL}$, $\mathrm{p}=0.04 ; 218.82 \pm 219.14$ vs. $41.67 \pm 69.12 \mathrm{ng} / \mathrm{mL}$, $\mathrm{p}=0.015)$.

Moreover, additional analysis revealed that the proportion of plasma concentration of AR-C124910XX to concentration of ticagrelor changed during observation according to different patterns in MTH group vs. no-MTH group. This proportion was lower in MTH group in comparison to no-MTH group during the first $2 \mathrm{~h}$. The similar ratios were observed $4 \mathrm{~h}$ after administration of ticagrelor LD ( $22.7 \%$ vs. $24.2 \%$ ), and later this proportion was higher in MTH group up to the end of observation, achieving the highest difference at $6 \mathrm{~h}(80.1 \%$ vs. $22.7 \%)$. Of note, none of 4 patients who died (all from MTH group) during the study observation period $(24 \mathrm{~h})$ had detectable plasma ticagrelor or AR-C124910XX.

\section{Discussion}

According to available research, this is the first study assessing the impact of OHCA treated with MTH on pharmacokinetics of ticagrelor in MI patients undergoing primary PCI.

Impaired bioavailability of ticagrelor expressed by lower total exposure, lower maximal plasma concentration and delayed maximal plasma concentration of the drug in patients undergoing MTH and $\mathrm{PCI}$ due to OHCA in the course of MI in comparison with patients treated with primary PCI for uncomplicated MI, advocates impaired gastrointestinal absorption of ticagrelor in critically ill patients undergoing therapeutic hypothermia. Moreover, presence of different AR-C124910XX formation rates between compared groups suggests potential diversity in drug metabolism and/or elimination. Recently, it has been reported that the presence of STEMI and diabetes are connected with impaired metabolism of ticagrelor during the first $6 \mathrm{~h}$ after ticagrelor LD for acute coronary syndrome [26]. In the current trial clear differences were observed in ticagrelor's active metabolite formation between patients with and without OHCA treated with MTH, however small the size of cardiac arrest, the survivor group did not allow formal conclusions to be drawn. This important issue requires clarification in further research.

Straub et al. [27] showed that adenosine diphosphate (ADP) plays a central role in hypothermia-induced platelet activation during hypothermia, suggesting that inhibition of ADP receptor binding has the potential to protect platelets against hypothermia-induced activation. However, in previously published studies insufficient efficacy of clopidogrel in patients undergoing MTH after OHCA was reported [28-32]. It was mostly explained by accelerated platelet turnover, increased platelet activation as well as by decreased bioavailability of clopidogrel due to its impaired absorption and diminished active metabolite generation $[1,28$, $33,34]$. The effect of ticagrelor and prasugrel in this clinical setting is not clear [35].

The high rate of stent thrombosis observed in some studies in resuscitated MI patients treated with MTH and primary PCI may be caused by insufficient inhibition of $\mathrm{P}_{2} \mathrm{Y}_{12}$ platelet receptors $[23,24,36-40]$. In an observational study published by Gouffran et al. [24], 10.9\% of OHCA survivors treated with MTH had stent thrombosis (the latter occurred in $4.2 \%$ of patients on clopidogrel, $18.2 \%$ on prasugrel, and $16.7 \%$ on ticagrelor). Jiménez-Brítez et al. [37] reported in-hospital stent thrombosis in $7.1 \%$ of patients, exclusively those treated with clopidogrel $(11.4 \%)$, while no stent thrombosis occurred in patients on ticagrelor or prasugrel. Joffre et al. [23] found cardiac arrest treated with MTH to be an independent risk factor for confirmed stent thrombosis (odds ratio $=12.9 ; 95 \%$ confidence interval 1.3-124.6, $\mathrm{p}=0.027)$ regardless of the type of $\mathrm{P} 2 \mathrm{Y}_{12}$ antagonist. Penela et al. [36] reported clinical resistance to clopidogrel with an extremely high incidence of acute stent thrombosis. In a small group of 11 MTH patients enrolled in the study, stent thrombosis occurred in $5(31.2 \%)$ cases, while 2 other patients experienced other thrombotic complications. Of note, most of the thrombotic complications occurred long after rewarming [36].

It is not clear if hypothermia itself or rather centralization of circulation in critically ill patients is responsible for impairment of ticagrelor absorption. The results of the ISAR-SHOCK registry demonstrated a weaker antiplatelet effect in shock patients receiving either clopidogrel or prasugrel without hypothermia [41]. This observation may suggest that the impaired effect of oral $\mathrm{P}_{2} \mathrm{Y}_{12}$ inhibitors in OHCA is related not only to hypothermia, but rather multifactorial [41, 42]. Regardless of what the exact mechanisms of ineffectiveness of these drugs are, intravenous infusion of a shortacting $\mathrm{P}_{2} \mathrm{Y}_{12}$ receptor antagonist - cangrelor — is capable of inhibiting life-threatening plateletmediated prothrombotic events in the setting of MTH. This innovative pharmacological strategy could significantly improve the safety of MTH [43-45]. Infusion of glycoprotein IIb/IIIa inhibitors 
is another therapeutic option allowing patients to overcome shortcomings of oral antiaggregatory agents, it is however, associated with markedly increased risk of bleedings [46-49]

\section{Limitations of the study}

The main limitation of the present study, which is similar to all previously published reports, is the low number of enrolled OHCA survivors treated with MTH and primary PCI. This did not permit the evaluation of clinical end points. Moreover, it was not possible herein, to differentiate the impact of MTH from consequences of local circulatory disorders. Also, the current trial did not evaluate pharmacodynamics of ticagrelor.

Nevertheless, careful monitoring of plasma concentrations of ticagrelor and AR-C124910XX at multiple time-points allowed us to demonstrate extensive differences in drug bioavailability between OHCA patients treated with MTH and primary PCI and patients with uncomplicated MI treated with primary PCI. Observations in the present research provide important evidence which may help to elucidate causes of the higher prevalence of stent thrombosis and other thrombotic events in patients undergoing MTH.

\section{Conclusions}

Bioavailability of ticagrelor is substantially decreased and delayed in MI patients treated with MTH after OHCA compared with patients with uncomplicated $\mathrm{MI}$ and without $\mathrm{OHCA}$ requiring MTH.

\section{Availability of data and material}

The datasets used and/or analysed during the current study are available from the corresponding author on reasonable request. The study protocol was published in Medical Research Journal: Umińska MJ, et al. Platelet reactivity during mild therapeutic hypothermia in patients with acute myocardial infarction treated with ticagrelor: study protocol of a single-centre study. Med Res J. 2016; 1(4): 115-119, doi: 10.5603/MRJ.2016.0021.

Funding: This study has been developed as part of the 'Diamentowy Grant' project financed by the Ministry of Science and Higher Education of the Republic of Poland from research funds for the years 2015-2018 (DI2014009144). The funder had no role in study design, data collection and analysis, decision to publish, or preparation of the manuscript.
Conflict of interest: J.M. Umińska: Beneficient of the "Diamentory Grant" financed by the Ministry of Science and Higher Education of the Republic of Poland from research funds for the years 2015-2018 (DI2014009144); K. Steblovnik and M. Noc: Beneficient of research grant from AstraZeneca; J. Kubica: Consulting fee from AstraZeneca.

\section{References}

1. Nolan JP, Soar J, Cariou A, et al. European Resuscitation Council and European Society of Intensive Care Medicine Guidelines for Post-resuscitation Care 2015: Section 5 of the European Resuscitation Council Guidelines for Resuscitation 2015. Resuscitation. 2015; 95: 202-222, doi: 10.1016/j.resuscitation.2015.07.018, indexed in Pubmed: 26477702.

2. Kubica J, Pstrągowski K, Adamski P, et al. Mild therapeutic hypothermia for patients with acute coronary syndrome and cardiac arrest treated with percutaneous coronary intervention (UNICORN). The design and rationale for the prospective, observational, multicenter study. Med Res J. 2016; 1(1): 23-27, doi: 10.5603/mrj.2016.0004.

3. Adamski P, Adamska U, Ostrowska M, et al. New directions for pharmacotherapy in the treatment of acute coronary syndrome. Expert Opin Pharmacother. 2016; 17(17): 2291-2306, doi: 10. 1080/14656566.2016.1241234, indexed in Pubmed: 27677394.

4. Kubica J. The optimal antiplatelet treatment in an emergency setting. Folia Med Copernicana. 2014; 2(3): 73-76.

5. Gurbel PA, Myat A, Kubica J, et al. State of the art: Oral antiplatelet therapy. JRSM Cardiovasc Dis. 2016; 5: 1-10, doi: 10.1177/2048004016652514, indexed in Pubmed: 27298725.

6. Dumas F, Rea TD. Long-term prognosis following resuscitation from out-of-hospital cardiac arrest: role of aetiology and presenting arrest rhythm. Resuscitation. 2012; 83(8): 1001-1005, doi: 10.1016/j.resuscitation.2012.01.029, indexed in Pubmed: 22306255.

7. Ibanez B, James S, Agewall S, et al. ESC Scientific Document Group. 2017 ESC Guidelines for the management of acute myocardial infarction in patients presenting with ST-segment elevation: The Task Force for the management of acute myocardial infarction in patients presenting with ST-segment elevation of the European Society of Cardiology (ESC). Eur Heart J. 2018; 39(2): 119-177, doi: 10.1093/eurheartj/ehx393, indexed in Pubmed: 28886621.

8. Kubica J, Adamski P, Paciorek P, et al. Treatment of patients with acute coronary syndrome: Recommendations for medical emergency teams: Focus on antiplatelet therapies. Updated experts' standpoint. Cardiol J. 2018; 25(3): 291-300, doi: 10.5603/ CJ.a2018.0042, indexed in Pubmed: 29671864.

9. Kubica J, Adamski P, Paciorek P, et al. Anti-aggregation therapy in patients with acute coronary syndrome - recommendations for medical emergency teams. Experts' standpoint. Kardiol Pol. 2017; 75(4): 399-408, doi: 10.5603/KP.a2017.0057, indexed in Pubmed: 28421594.

10. Navarese EP, Verdoia M, Schaffer A, et al. Ischaemic and bleeding complications with new, compared to standard, ADP-antagonist regimens in acute coronary syndromes: a meta-analysis of randomized trials. QJM. 2011; 104(7): 561-569, doi: 10.1093/ qjmed/hcr069, indexed in Pubmed: 21572108.

11. Navarese EP, Buffon A, Kozinski M, et al. A critical overview on ticagrelor in acute coronary syndromes. QJM. 2013; 106(2): 105-115, doi: 10.1093/qjmed/hcs187, indexed in Pubmed: 23097390. 
12. Kozinski M, Pstragowski K, Kubica JM, et al. ACS networkbased implementation of therapeutic hypothermia for the treatment of comatose out-of-hospital cardiac arrest survivors improves clinical outcomes: the first European experience. Scand J Trauma Resusc Emerg Med. 2013; 21: 22, doi: 10.1186/17577241-21-22, indexed in Pubmed: 23531402.

13. Adamski P, Sikora J, Laskowska E, et al. Comparison of bioavailability and antiplatelet action of ticagrelor in patients with ST-elevation myocardial infarction and non-ST-elevation myocardial infarction: A prospective, observational, single-centre study. PLoS One. 2017; 12(10): e0186013, doi: 10.1371/journal. pone.0186013, indexed in Pubmed: 29023473.

14. Adamski P, Ostrowska M, Sikora J, et al. Comparison of Ticagrelor Pharmacokinetics and Pharmacodynamics in STEMI and NSTEMI Patients (PINPOINT): protocol for a prospective, observational, single-centre study. BMJ Open. 2017; 7(4): e013218, doi: 10.1136/bmjopen-2016-013218, indexed in Pubmed: 28446521.

15. Kubica J, Kubica A, Jilma B, et al. Impact of morphine on antiplatelet effects of oral P2Y12 receptor inhibitors. Int J Cardiol. 2016; 215: 201-208, doi: 10.1016/j.ijcard.2016.04.077, indexed in Pubmed: 27128531.

16. Kubica J, Adamski P, Ostrowska M, et al. Morphine delays and attenuates ticagrelor exposure and action in patients with myocardial infarction: the randomized, double-blind, placebo-controlled IMPRESSION trial. Eur Heart J. 2016; 37(3): 245-252, doi: 10.1093/eurheartj/ehv547, indexed in Pubmed: 26491112.

17. Niezgoda P, Sikora J, Barańska M, et al. Crushed sublingual versus oral ticagrelor administration strategies in patients with unstable angina. A pharmacokinetic/pharmacodynamic study. Thromb Haemost. 2017; 117(4): 718-726, doi: 10.1160/TH1608-0670, indexed in Pubmed: 28203684.

18. Adamski P, Koziński M, Ostrowska M, et al. Overview of pleiotropic effects of platelet P2Y12 receptor inhibitors. Thromb Haemost. 2014; 112(2): 224-242, doi: 10.1160/TH13-11-0915, indexed in Pubmed: 24763899.

19. Kubica J, Adamski P, Ostrowska M, et al. Influence of Morphine on Pharmacokinetics and Pharmacodynamics of Ticagrelor in Patients with Acute Myocardial Infarction (IMPRESSION): study protocol for a randomized controlled trial. Trials. 2015; 16: 198, doi: 10.1186/s13063-015-0724-z, indexed in Pubmed: 25925591.

20. Tilemann LM, Stiepak J, Zelniker T, et al. Efficacy of enteral ticagrelor in hypothermic patients after out-of-hospital cardiac arrest. Clin Res Cardiol. 2016; 105(4): 332-340, doi: 10.1007/ s00392-015-0925-1, indexed in Pubmed: 26508414.

21. Umińska J, Koziński M, Pstragowski K, et al. Platelet reactivity during mild therapeutic hypothermia in patients with acute myocardial infarction treated with ticagrelor: study protocol of a single-centre study. Med Res J. 2017; 1(4): 115-119, doi: 10.5603/mrj.2016.0021.

22. Kubica A, Kasprzak M, Siller-Matula J, et al. Time-related changes in determinants of antiplatelet effect of clopidogrel in patients after myocardial infarction. Eur J Pharmacol. 2014; 742: 47-54, doi: 10.1016/j.ejphar.2014.08.009, indexed in Pubmed: 25199965.

23. Joffre J, Varenne O, Bougouin W, et al. Stent thrombosis: an increased adverse event after angioplasty following resuscitated cardiac arrest. Resuscitation. 2014; 85(6): 769-773, doi: 10.1016/j. resuscitation.2014.02.013, indexed in Pubmed: 24572484.

24. Gouffran G, Rosencher J, Bougouin W, et al. Stent thrombosis after primary percutaneous coronary intervention in comatose survivors of out-of-hospital cardiac arrest: Are the new P2Y12 inhibitors really more effective than clopidogrel? Resuscitation.
2016; 98: 73-78, doi: 10.1016/j.resuscitation.2015.11.006, indexed in Pubmed: 26610376.

25. Tantry US, Bonello L, Aradi D, et al. Consensus and update on the definition of on-treatment platelet reactivity to adenosine diphosphate associated with ischemia and bleeding. J Am Coll Cardiol. 2013; 62(24): 2261-2273, doi: 10.1016/j.jacc.2013.07.101, indexed in Pubmed: 24076493.

26. Adamski P, Buszko K, Sikora J, et al. Metabolism of ticagrelor in patients with acute coronary syndromes. Sci Rep. 2018; 8(1): 11746, doi: 10.1038/s41598-018-29619-9, indexed in Pubmed: 30082687.

27. Straub A, Breuer M, Wendel HP, et al. Critical temperature ranges of hypothermia-induced platelet activation: possible implications for cooling patients in cardiac surgery. Thromb Haemost. 2007; 97(4): 608-616, indexed in Pubmed: 17393024.

28. Prüller F, Milke OL, Bis L, et al. Impaired aspirin-mediated platelet function inhibition in resuscitated patients with acute myocardial infarction treated with therapeutic hypothermia: a prospective, observational, non-randomized single-centre study. Ann Intensive Care. 2018; 8(1): 28, doi: 10.1186/s13613018-0366-x, indexed in Pubmed: 29468430.

29. Moudgil R, Al-Turbak H, Osborne C, et al. CAPITAL Investigators. Superiority of ticagrelor over clopidogrel in patients after cardiac arrest undergoing therapeutic hypothermia. Can J Cardiol. 2014; 30(11): 1396-1399, doi: 10.1016/j.cjca.2014.07.745, indexed in Pubmed: 25442437.

30. Ferreiro J, Sánchez-Salado J, Gracida M, et al. Impact of Mild Hypothermia on Platelet Responsiveness to Aspirin and Clopidogrel: an In Vitro Pharmacodynamic Investigation. J Cardiovasc Transl Res. 2014; 7(1): 39-46, doi: 10.1007/s12265-013-9533-5.

31. Rosencher J, Gouffran G, Bougouin W, et al. Optimal antiplatelet therapy in out-hospital cardiac arrest patients treated by primary percutaneous coronary intervention. Resuscitation. 2015; 90: e7-e8, doi: 10.1016/j.resuscitation.2015.02.030, indexed in Pubmed: 25758639.

32. Bednar F, Kroupa J, Ondrakova M, et al. Antiplatelet efficacy of P2Y12 inhibitors (prasugrel, ticagrelor, clopidogrel) in patients treated with mild therapeutic hypothermia after cardiac arrest due to acute myocardial infarction. J Thromb Thrombolysis. 2016; 41(4): 549-555, doi: 10.1007/s11239-015-1274-7, indexed in Pubmed: 26340851.

33. Ibrahim K, Christoph M, Schmeinck S, et al. High rates of prasugrel and ticagrelor non-responder in patients treated with therapeutic hypothermia after cardiac arrest. Resuscitation. 2014; 85(5): 649-656, doi: 10.1016/j.resuscitation.2014.02.004, indexed in Pubmed: 24555950.

34. Kander T, Dankiewicz J, Friberg H, et al. Platelet aggregation and clot formation in comatose survivors of cardiac arrest treated with induced hypothermia and dual platelet inhibition with aspirin and ticagrelor; a prospective observational study. Crit Care. 2014; 18(5): 495, doi: 10.1186/s13054-014-0495-z, indexed in Pubmed: 25292183.

35. Schoergenhofer C, Hobl EL, Staudinger T, et al. Prasugrel in critically ill patients. Thromb Haemost. 2017; 117(8): 1582-1587, doi: 10.1160/TH17-03-0154, indexed in Pubmed: 28692105.

36. Penela D, Magaldi M, Fontanals J, et al. Hypothermia in acute coronary syndrome: brain salvage versus stent thrombosis? J Am Coll Cardiol. 2013; 61(6): 686-687, doi: 10.1016/j. jacc.2012.10.029, indexed in Pubmed: 23265329.

37. Jiménez-Britez G, Freixa X, Flores-Umanzor E, et al. Out-ofhospital cardiac arrest and stent thrombosis: Ticagrelor versus 
clopidogrel in patients with primary percutaneous coronary intervention under mild therapeutic hypothermia. Resuscitation. 2017; 114: 141-145, doi: 10.1016/j.resuscitation.2017.02.015, indexed in Pubmed: 28242212.

38. Bjelland TW, Hjertner $\varnothing$, Klepstad P, et al. Antiplatelet effect of clopidogrel is reduced in patients treated with therapeutic hypothermia after cardiac arrest. Resuscitation. 2010; 81(12): 1627-1631, doi: 10.1016/j.resuscitation.2010.07.002, indexed in Pubmed: 20727659.

39. Ibrahim K, Christoph M, Schmeinck S, et al. Clopidogrel and prasugrel non-responder in therapeutic hypothermia after cardiac arrest. Eur Heart J . 2012; 33: 315.

40. Steblovnik K, Blinc A, Mijovski MB, et al. Ticagrelor Versus Clopidogrel in Comatose Survivors of Out-of-Hospital Cardiac Arrest Undergoing Percutaneous Coronary Intervention and Hypothermia: A Randomized Study. Circulation. 2016; 134(25): 2128-2130, doi: 10.1161/CIRCULATIONAHA.116.024872, indexed in Pubmed: 27994027.

41. Orban M, Mayer K, Morath T, et al. The impact of therapeutic hypothermia on on-treatment platelet reactivity and clinical outcome in cardiogenic shock patients undergoing primary PCI for acute myocardial infarction: Results from the ISAR-SHOCK registry. Thromb Res. 2015; 136(1): 87-93, doi: 10.1016/j.thromres.2015.04.029, indexed in Pubmed: 25976448.

42. Ratcovich H, Sadjadieh G, Andersson HB, et al. The effect of TIcagrelor administered through a nasogastric tube to COMAtose patients undergoing acute percutaneous coronary intervention: the TICOMA study. EuroIntervention. 2017; 12(14): 1782-1788, doi: 10.4244/EIJ-D-16-00398, indexed in Pubmed: 28216475.

43. Droppa M, Borst O, Rath D, et al. Impact of Intravenous P2Y12-Receptor Inhibition with Cangrelor in Patients Present- ing with Acute Coronary Syndrome and Cardiogenic Shock a Case Series. Cell Physiol Biochem. 2017; 42(4): 1336-1341, doi: 10.1159/000478962, indexed in Pubmed: 28700987.

44. Krajewski S, Kurz J, Neumann B, et al. Short-acting P2Y12 blockade to reduce platelet dysfunction and coagulopathy during experimental extracorporeal circulation and hypothermia. $\mathrm{Br}$ J Anaesth. 2012; 108(6): 912-921, doi: 10.1093/bja/aer518, indexed in Pubmed: 22369765.

45. Kubica J, Kozinski M, Navarese EP, et al. Cangrelor: an emerging therapeutic option for patients with coronary artery disease. Curr Med Res Opin. 2014; 30(5): 813-828, doi: 10.1185/030079 95.2014.880050, indexed in Pubmed: 24393016.

46. Kubica A, Kozinski M, Navarese EP, et al. Intracoronary versus intravenous abciximab administration in STEMI patients: overview of current status and open questions. Curr Med Res Opin. 2011; 27(11): 2133-2144, doi: 10.1185/03007995.2011.621417, indexed in Pubmed: 21942506.

47. Kubica J, Koziński M, Navarese EP, et al. Updated evidence on intracoronary abciximab in ST-elevation myocardial infarction: a systematic review and meta-analysis of randomized clinical trials. Cardiol J. 2012; 19(3): 230-242, indexed in Pubmed: 22641541.

48. Navarese EP, Kozinski M, Obonska K, et al. Clinical efficacy and safety of intracoronary vs. intravenous abciximab administration in STEMI patients undergoing primary percutaneous coronary intervention: a meta-analysis of randomized trials. Platelets. 2012; 23(4): 274-281, doi: 10.3109/09537104.2011.619602, indexed in Pubmed: 21988317.

49. Siller-Matula JM, Specht S, Kubica J, et al. Abciximab as a bridging strategy to overcome morphine-prasugrel interaction in STEMI patients. Br J Clin Pharmacol. 2016; 82(5): 1343-1350, doi: 10.1111/bcp.13053, indexed in Pubmed: 27366874. 